https://doi.org/10.37208/tgn27114

\section{Largest wild crab apple (Malus sylvestris (Linnaeus) Mill.) in Scotland on the shores of Loch Lomond}

\author{
C.J. McInerny ${ }^{1} \&$ R. Gray ${ }^{2}$ \\ ${ }^{1}$ School of Life Sciences, University of Glasgow, \\ Glasgow G12 8QQ \\ 2 "Langdale", 6 Prince Albert Road, Glasgow G12 9JX \\ ${ }^{1}$ E-mail: chris.mcinerny@glasgow.ac.uk
}

While completing wildlife surveys on the east shore of Loch Lomond an unusually large crab apple (Malus sylvestris (Linnaeus) Mill.) was found (Fig. 1A,B). In October 2016 its height was measured as $12 \mathrm{~m}$. This height is exceeded by a crab apple of $17 \mathrm{~m}$ recorded at Tunbridge Wells, Kent in the database of the Tree Register of the British Isles (TROBI) (2017). However, the girth of the Loch Lomond tree of $410 \mathrm{~cm}$ measured at $0.5 \mathrm{~m}$ above ground level (a.g.l.) in April 2017 (Fig. 2) makes it apparently the Champion Tree of its species for Britain and Ireland, as listed by TROBI. One other, a huge tree $550 \mathrm{~cm}$ in girth (at $0.5 \mathrm{~m}$ a.g.1.), located at Brignall, Barnard Castle, Co. Durham is a coppice and so not eligible as a Champion Tree (although it may be the largest by volume). According to the TROBI database (2017) the crab apples closest in girth to the Loch Lomond tree are: Clapgate Gill,
Richmond, North Yorkshire, $420 \mathrm{~cm}$ "fallen but alive" (2010); Tipperary, Ireland, $401 \mathrm{~cm}$ at $0.5 \mathrm{~m}$ a.g.1. (2010); Croxdale Hall Park, Co. Durham, $355 \mathrm{~cm}$; Stobo, Peebles, Borders, $290 \mathrm{~cm}$ (2012); and St. Boswells, Borders, $242 \mathrm{~cm}$ at $1.5 \mathrm{~m}$ a.g.1. (2002).

The crab apple, the only native apple tree in the UK, is present throughout Scotland, including some islands, but with most found in the southern half of the country (NBN Atlas, 2017). However, increasingly, it is becoming rare throughout its European range due to a combination of the low economic value of both the timber and fruit, and with the species having limited competitive growth characteristics, being usually relatively short and having high light requirements (Stephan et al., 2003; Wagner et al., 2014). Furthermore, the genetic integrity of the wild crab apple is threatened by the spread of the domesticated orchard apple (Malus $\mathrm{x}$ domestica Borkh.) with which M. sylvestris hybridizes (Larsen et al., 2006; Wagner et al., 2014). Studies of chloroplast DNA variation in trees across Europe revealed that up to $11 \%$ of M. sylvestris were hybrids with $M$. x domestica (Coart et al., 2006).

To confirm the status of the Loch Lomond crab apple it was important to establish that it was $M$. sylvestris and not M. x domestica, or a hybrid between the two. $M$. sylvestris can be identified by examination of features including the shoots, leaves, flowers and fruit. Importantly, genetic analysis has shown that there is much variation in some of these features with, consequently, leaf hairiness (pubescence) and fruit size thought to be the most reliable way to distinguish the two species and hybrids (Wagner et al., 2014).

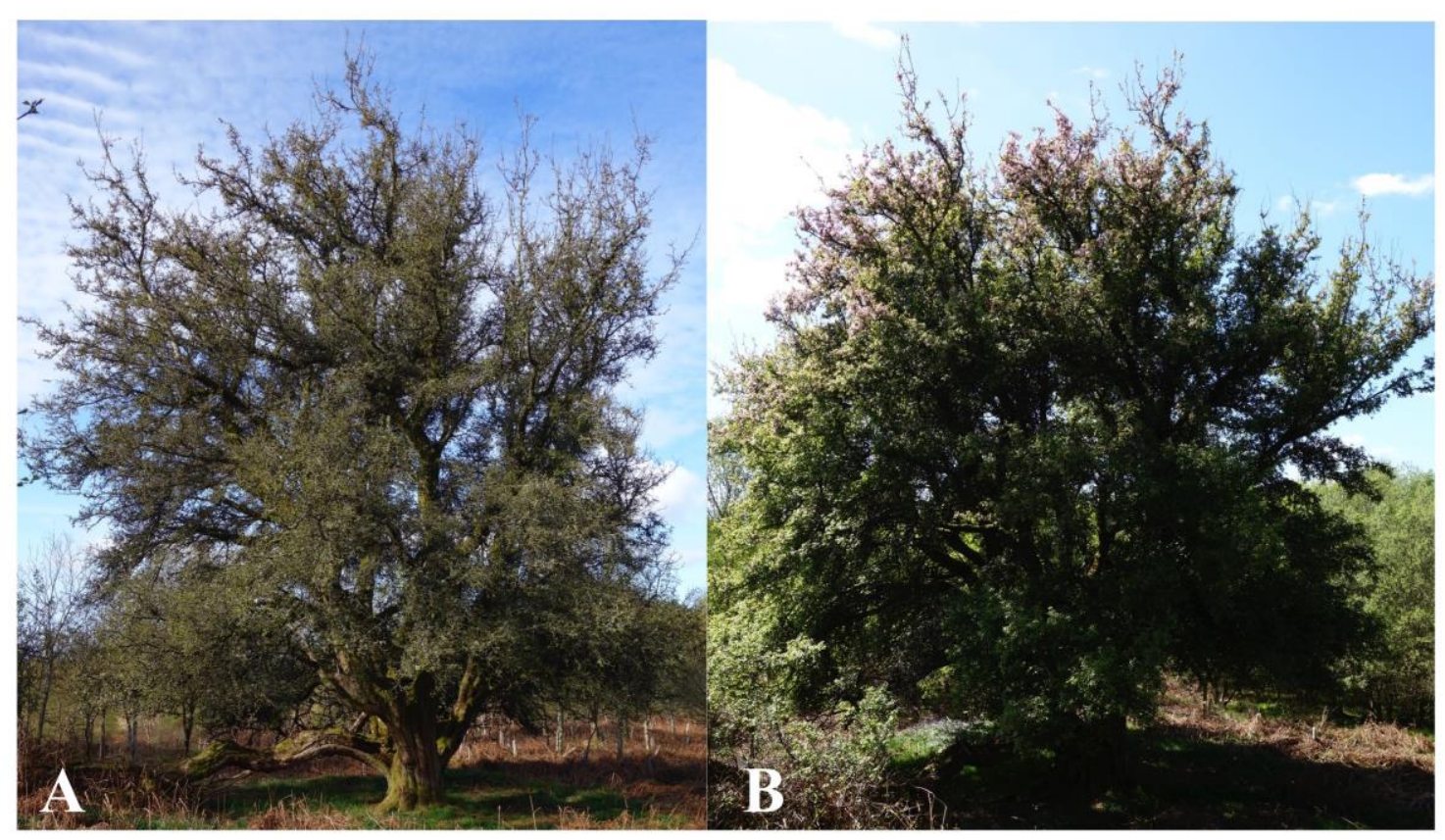

Fig. 1. A crab apple (Malus sylvestris) growing on the shores of Loch Lomond in 2017, 23rd April (A) and 9th May (B). It was $12 \mathrm{~m}$ in height, unusually tall for the species. (Photos: C. McInerny) 


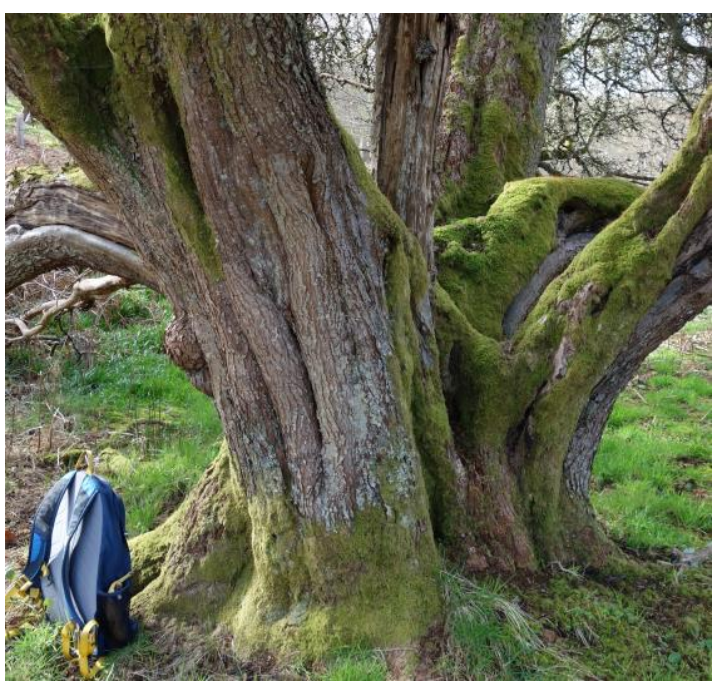

Fig. 2. The trunk of a crab apple (Malus sylvestris) growing on the shores of Loch Lomond, 23rd April 2017. Its girth of $410 \mathrm{~cm}$, measured at $0.5 \mathrm{~m}$ above ground level (a.g.l.), makes it the largest recorded example of the species in Scotland and the Champion Tree of its species for Britain and Ireland, as listed by the Tree Register of the British Isles (TROBI) (2017). (Photo: C. McInerny)

\section{Leaf hairiness (pubescence)}

M. sylvestris leaves are almost hairless, $c a .6 \mathrm{~cm}$ in size, oval in shape and with small triangular teeth, while the leaves of $M$. x domestica and hybrids are larger, woolly beneath and have irregular teeth (Wagner et al., 2014). The difference in leaf hairiness is most noticeable in late summer and autumn. Similarly in spring the shoots are hairless, whereas the shoots of $M$. x domestica and hybrids are slightly hairy.

On examination, the leaves of the Loch Lomond tree in April 2017 were found to be hairless, small (equal to or less than $6 \mathrm{~cm}$ ), oval and with small triangular teeth (Fig. 3B,C). The leaves remained hairless through to October (Fig. 3C). Likewise the shoots in April 2017 were found to be hairless. These characteristics indicate M. sylvestris (Wagner et al., 2014).

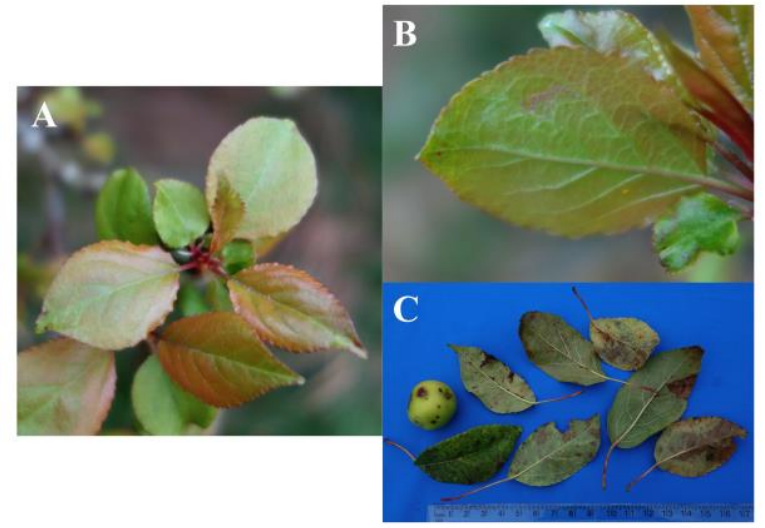

Fig. 3. The upper leaf (A) and lower leaf (B) of a crab apple (Malus sylvestris) growing on the shores of Loch Lomond, 30th April 2017. The lack of leaf hair remained until autumn (B), these photographed on 8th October 2017. That the leaves lack hair (pubescence), particularly on the underside, is characteristic of the species and excludes both the orchard apple (M. x domestica) and hybrids of M. sylvestris and M. $\mathrm{x}$ domestica. (Photos: C. McInerny)

\section{Flower colour}

The flowers of $M$. sylvestris are largely white, developing from pink buds (Wagner et al., 2014). Instead, $M$. x domestica produces white flowers with pink shading from rich pink buds. Hybrids trees also produce pinker flowers.

On examination, the buds and flowers of the Loch Lomond tree in May 2017 were found to be pink on first emergence (Fig. 4A,B), but becoming mainly white on maturity (Fig. 4C,D). A few of the mature flowers had some pink (Fig. 4D), but the majority were mostly white. Again this is consistent with M. sylvestris.

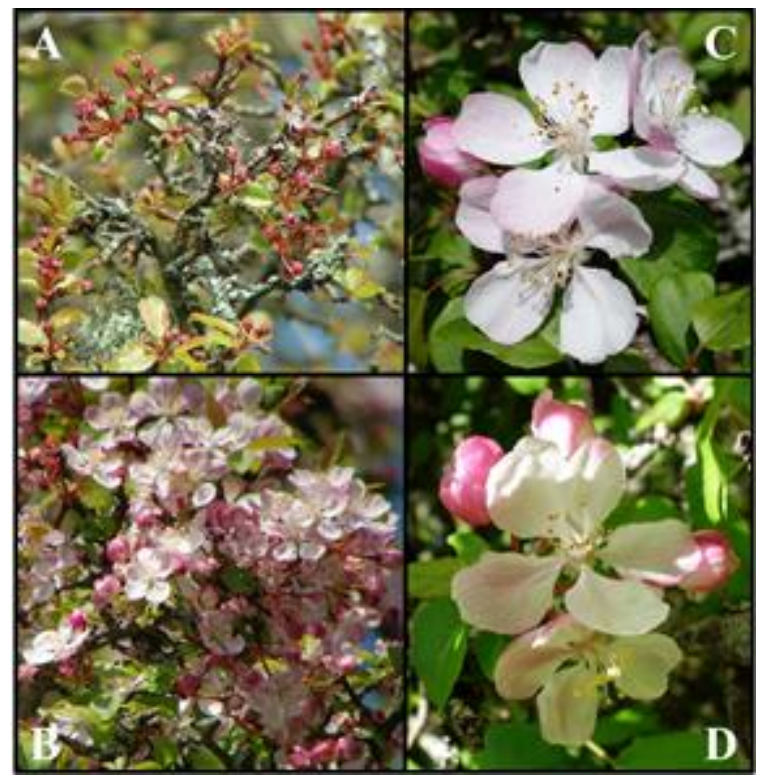

Fig. 4. The shoots (A) and flowers (B-D) of a crab apple (Malus sylvestris) growing on the shores of Loch Lomond, 23rd April and 9th May 2017. That the flowers are mostly white is a characteristic of the species. (Photos: C. McInerny)

\section{Fruit size}

M. sylvestris fruits are less than $40 \mathrm{~mm}$, whereas fruits of $M$. x domestica are at least $40 \mathrm{~mm}$ and even larger in hybrids (Wagner et al., 2014). The fruit size of the Loch Lomond tree was measured in October 2017 with the apples found to be $20-30 \mathrm{~mm}$ (Fig. 5A,B) indicating M. sylvestris.

This combination of observations suggests that the Loch Lomond tree is a wild crab apple $M$. sylvestris and as such is the largest reported living specimen in Scotland. A tree of this size is likely to be at least 160 years old. We plan to list it with TROBI (2017) as the Champion Tree of this species for Britain and Ireland.

For those who wish to view this magnificent living organism it can be found at the Cashel Forest Reserve (http://www.cashel.org.uk/index.html), $6 \mathrm{~km}$ north of Balmaha on the east shore of Loch Lomond. The tree is at the south corner of "Memorial Way", also known as the "Blue Loop", most easily seen about $100 \mathrm{~m}$ further southeast along the "Red Loop" trail at NS4020093751. 


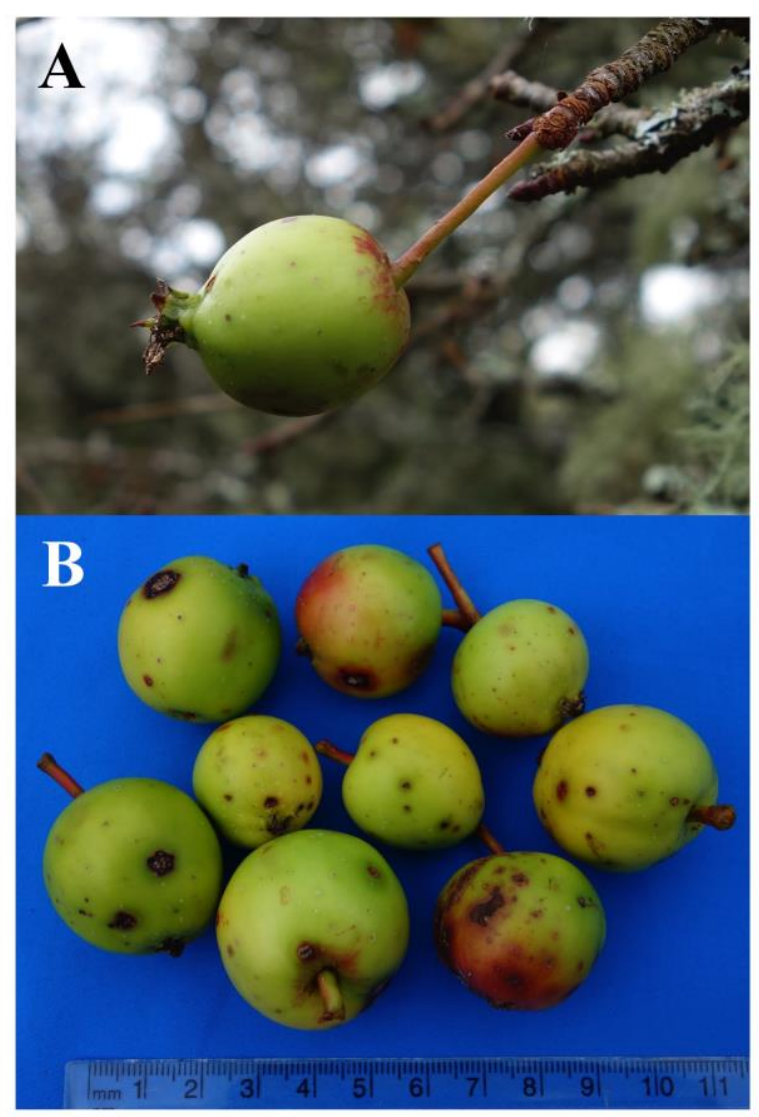

Fig. 5. Fruits (A,B) of a crab apple (Malus sylvestris) growing on the shores of Loch Lomond, 8th October 2017. That the fruits are smaller than $40 \mathrm{~mm}$ is indicative of the species, and excludes the both the orchard apple (M. x domestica) and hybrids of $M$. sylvestris and $M$. x domestica. (Photos: C. McInerny)

\section{ACKNOWLEDGEMENTS}

We thank Fiona Inches of The Royal Botanic Garden Edinburgh for advice on crab apple identification, and David Alderman of TROBI for information on the Champion Tree listings. We thank an anonymous reviewer for improvements to the text.

\section{REFERENCES}

Coart, E., Van Glabeke, S., De Loose, M., Larsen, A.S. \& Roldán-Ruiz, I. (2006). Chloroplast diversity in the genus Malus: new insights into the relationship between the European wild apple (Malus sylvestris (L.) Mill.) and the domesticated apple (Malus domestica Borkh.). Molecular Ecology 15, 21712182.

https://doi.org/10.1111/j.1365-294X.2006.02924.X

Larsen, A.S., Asmussen, C.B., Coart, E., Olrik, D.C. \& Kjær, E.D. (2006). Hybridization and genetic variation in Danish populations of European crab apple (Malus sylvestris). Tree Genetics and Genomes 2, 86-97. https://doi.org/10.1007/s11295-005-0030-0

National Biodiversity Network (NBN) Atlas (2017). https://www.nbnatlas.org Accessed 24th October 2017.

Stephan, B.R., Wagner, I. \& Kleinschmit, J. (2003). Wild apple and pear - Malus sylvestris/Pyrus pyraster: Technical guidelines of genetic conservation and use. European Forest Genetic Resources Programme.

http://www.euforgen.org/fileadmin//templates/eufor gen.org/upload/Publications/Technical_guidelines/9 22_Technical_guidelines_for_genetic_conservation _and_use_for_wild_apple_and_pear_Malus_sylve stris_and_Pyrus_pyraster_.pdf

The Tree Register of the British Isles (TROBI) (2017). http://www.treeregister.org/ Accessed 24th October 2017.

Wagner I., Maurer, W.D., Lemmen, P., Schmitt, H.P., Wagner, M., Binder, M. \& Patzak, P. (2014). Hybridization and genetic diversity in wild apple (Malus sylvestris (L.) Mill.) from various regions in Germany and from Luxembourg. Silvae Genetica $63,81-94$. https://doi.org/10.1515/sg-2014-0012 